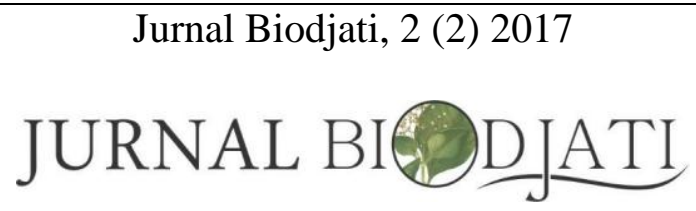

http://journal.uinsgd.ac.id/index.php/biodjati

\title{
ASOSIASI MAKROALGA DENGAN GASTROPODA PADA ZONA INTERTIDAL PANTAI PANANJUNG PANGANDARAN
}

\author{
Tri Dewi Kusumaningrum Pribadi ${ }^{1}$, Ramdan Nurdiana ${ }^{2}$, Keukeu Kaniawati Rosada ${ }^{3}$ \\ ${ }^{1,2,3}$ Departemen Biologi, Fakultas Matematika dan Ilmu Pengetahuan Alam, Universtas Padjadjaran
}

\begin{tabular}{l}
\hline Diterima 10 September \\
2017 \\
Disetujui 24 November \\
2017 \\
Publish 30 November \\
2017 \\
\hline J1. Raya Bandung Sumedang \\
km 21, Jatinangor 45363. \\
Telp/fax. +62227796412 \\
e-mail: \\
${ }^{1}$ tridewi.pribadi@unpad.ac.id, \\
${ }^{2}$ ramdan.amoeba@yahoo.com, \\
${ }^{3}$ keukeu@unpad.ac.id, \\
\hline
\end{tabular}

e-ISSN : 2541-4208

p-ISSN : 2548-1606

\begin{abstract}
Abstrak. Interaksi yang terjadi antar organisme dengan lingkungannya merupakan proses yang kompleks, karena setiap komponen lingkungan tidak berdiri sendiri, melainkan selalu berhubungan dan saling memengaruhi baik secara langsung maupun tidak langsung. Keberadaan maupun ketiadaan suatu populasi dalam komunitas tertentu dapat memberikan gambaran tentang kondisi komunitas tersebut. Untuk mengetahui pola interaksi pada komunitas padang lamun di zona intertidal Pantai Pananjung Pangandaran, dilakukan penelitian tentang asosiasi antara populasi makroalga dan gastropoda. Pengukuran indeks ekologis diperoleh melalui observasi kuantitatif populasi makroalga dan gastropoda pada transek garis sepanjang $200 \mathrm{~m}$ sejajar garis pantai dengan plot kuadrat, di dua lokasi studi yang memiliki karakteristik biofisik yang berbeda, yaitu Pantai Pasir Putih dan Pantai Batu Nunggul. Hasil menunjukan bahwa di lokasi studi Pantai Pasir Putih terdapat 12 spesies makroalga dan 7 spesies gastropoda. Di lokasi studi Pantai Batu Nunggul terdapat 11 spesies makroalga dan 8 spesies gastropoda. Tutupan Makroalga tertinggi terdapat di kawasan Pantai Batu Nunggul dengan jenis Gracilaria coronopifolia sebesar 57,5\%. Kepadatan Gastropoda tertinggi terdapat di lokasi studi Pantai Batu Nunggul, yaitu Cypraea annulus. Asosiasi antara makroalga dengan gastropoda di kedua lokasi studi menunjukkan asosiasi positif namun tidak terjadi ketergantungan antara kedua populasi tersebut.
\end{abstract}

Kata Kunci: Asosiasi, Gastropoda, Makroalga, Pangandaran.

Abstract. Interaction among organisms and the environment is a complex process, for each component is related one another either indirectly or directly. The presence or absence of one population in community illustrate the condition of the community as a whole. Study of interaction between gastropode and macroalgae in the seagrass beds located in Pananjung Pangandaran intertidal zone has been conducted to observe interaction pattern. Ecological Index measured by performing quantitative observation on macroalgae and gastropode population. Samples were taken from two locations with different bio-physical characteristic, Pasir Putih Beach and Batu Nunggul Beach of Pananjung Pangandaran. Transect of $200 \mathrm{~m}$ with plots and parallel to shoreline were materialized to matrix the sampling. Results showed that 12 macroalgae species and 7 species of gastropode explored in the Pasir Putih Beach, while in the Batu Nunggul Beach 11 macroalgae species and 8 species of gastropode. The highest macroalgal coverage showed by Gracilaria 


\section{JURNAL BIODJATI}

http://journal.uinsgd.ac.id/index.php/biodjati

coronopifolia (57.5\%) in the Batu Nunggul Beach. The highest gastropode density was in the Batu Nunggul Beach, Cypraea annulus. Association between macroalgae and gastropode in both studi site was positive, but there was no dependency between the two populations.

Key words: Assossiation, Gastropode, Macroalgae, Pangandaran.

\section{Cara Sitasi}

Pribadi, T. D. K., Nurdiana, R. \& Rosada, K. K. (2017). Asosiasi Makroalga dengan Gastropoda pada Zona Intertidal Pantai Pananjung Pangandaran. Jurnal Biodjati, 2 (2), Hal 107-114.

\section{PENDAHULUAN}

Zona intertidal merupakan daerah pasang surut yang dipengaruhi oleh kegiatan daratan (pantai) dan laut. Kondisi komunitas makroalga dan gastropoda di zona pasang surut tidak banyak perubahan kecuali pada kondisi ekstrim tertentu dapat merubah komposisi dan kelimpahan organisme intertidal. Zona ini merupakan daerah yang paling sempit bila dilihat dari luasannya, namun memiliki keragaman dan kelimpahan organisme yang relatif lebih tinggi dibandingkan dengan habitat laut lainnya (Yulianda, 2013).

Suatu komunitas yang terbentuk atas banyak spesies, sebagian diantaranya akan dipengaruhi oleh kehadiran atau ketidakhadiran anggota spesies lain dari komunitas tersebut. Seringkali dua atau lebih spesies berinteraksi, yang bersifat positif bila menguntungkan kedua pihak, atau negatif dalam artian merugikan bagi salah satu pihak (Odum, 1993).

Keberadaan makroalga pada komunitas padang lamun merupakan hal yang penting bagi ekosistem, karena selain sebagai produsen primer dan sumber makanan bagi herbivora, kanopi makroalga juga menjadi habitat berbagai jenis biota laut. Dalam ekosistem padang lamun, keberadaan herbivora yang membawa efek positif pada makroalga menjadi hal yang menarik untuk diteliti. Penelitian Guidone et al. (2010) menunjukkan bahwa peningkatan pertumbuhan makroalga dipengaruhi adanya hewan herbivora, terutama melalui dua mekanisme, yaitu penyediaan nutrisi melalui ekskresi dari hewan herbivora dan penghapusan epifit.

Penelitian ini bertujuan untuk mengetahui interaksi yang terjadi antara makroalga dan hewan moluska terutama famili Gastropoda. Dengan analisis kepadatan, frekuensi, tutupan, kesamaan komunitas, dan keanekaragaman, dapat diketahui asosiasi yang terjadi antara makroalga dengan gastropoda. Selain itu juga dapat mengetahui kecenderungan relung ekologi dari gastropoda terhadap makroalga di dua lokasi penelitian yang berbeda, yang mewakili dua karakteristik pantai yang berbeda. Diharapkan dengan mengetahui asosiasi kedua komunitas tersebut, maka dapat memberikan informasi untuk mempertahankan keberadaan sekaligus diversitasnya.

\section{BAHAN DAN METODE.}

Kawasan Konservasi Sumber Daya Alam Pangandaran merupakan daerah semenanjung yang terdapat di barisan selatan Pulau Jawa dan berbatasan langsung dengan Samudera Hindia. Kawasan ini berada pada koordinat $70^{\circ} 30^{\prime}-80^{\circ}$ LS dan $108^{\circ} 30^{\prime}-109^{\circ}$ BT. Keadaan topografinya landai dengan ketinggian berkisar 0-20 $\mathrm{m}$ di atas permukaan laut. Observasi dilakukan pada dua stasiun yang mewakili Taman Wisata Alam dan Cagar Alam Pananjung Pangandaran (Gambar 1). 


\section{JURNAL BIODJATI}

http://journal.uinsgd.ac.id/index.php/biodjati
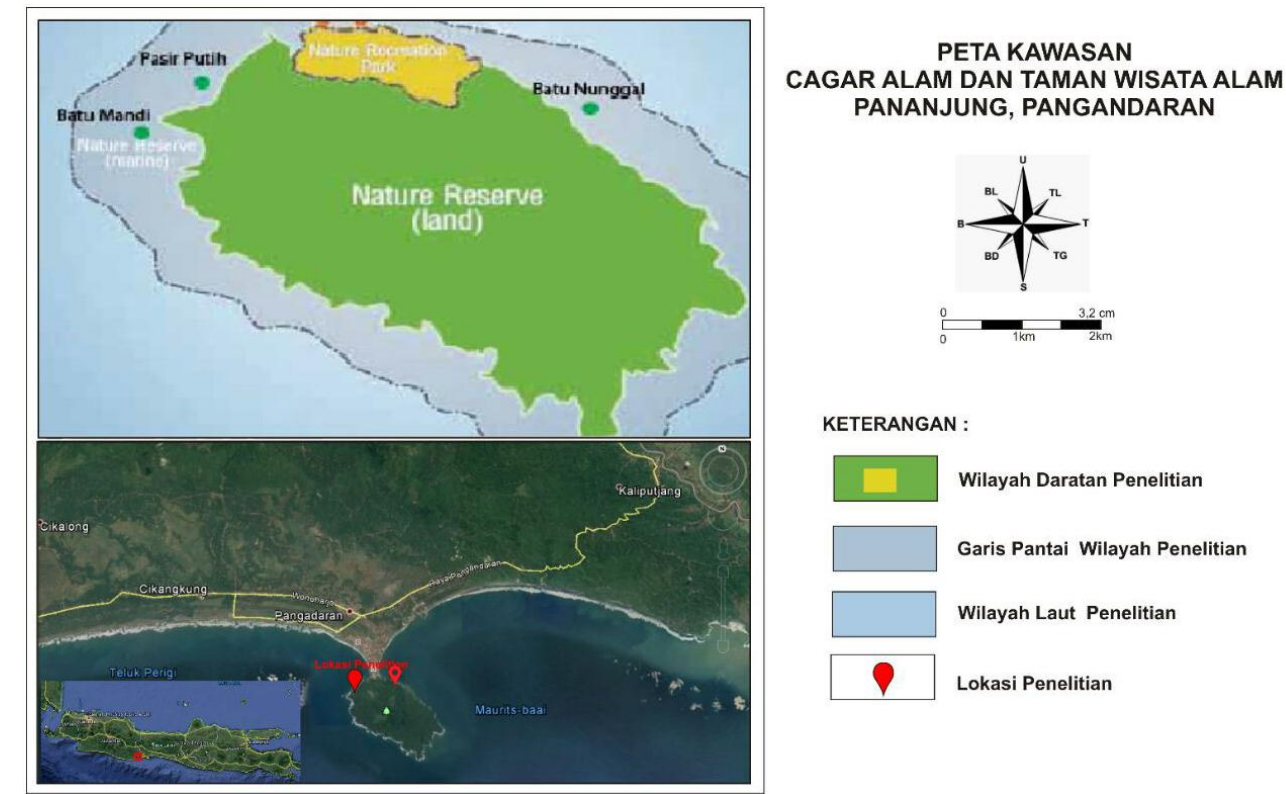

KETERANGAN :

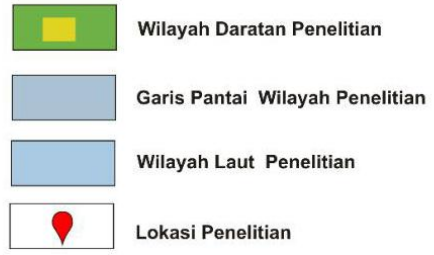

Gambar 1. Peta lokasi penelitian di Pananjung Pangandaran dan stasiun pengamatan (BKSDA Taman Wisata dan Cagar Alam Pangandaran, 2016).

Pengambilan data makroalga dan gastropoda dilakukan dengan mengacu pada metode English (1994) yang sudah dimodifikasi untuk ukuran kuadran dan interval jarak. Pengambilan sampel dilakukan dengan menggunakan kuadran (1x1 meter) yang diletakkan pada garis transek sepanjang 200 meter, dengan interval $50 \mathrm{~m}$. Gastropoda dan makroalga yang ditemukan dalam kuadran dicatat dan diambil gambarnya untuk identifikasi di Laboratorium Ekologi Perairan Universitas Padjadjaran. Pengukuran parameter abiotik dilakukan untuk melihat kondisi kimia-fisik perairan saat observasi, termasuk sampel air untuk analisis parameter lingkungan meliputi suhu, salinitas, kedalaman air, dan kadar amonium.

Indeks ekologi yang ditampilkan untuk makroalga adalah Indeks Nilai Penting dan \% tutupan (Gomez \& Yap, 1988), sedangkan untuk Gastropoda adalah Indeks Nilai Penting dan kepadatan (Brower et al., 1998). Kemudian dilakukan analisis statistik untuk melihat korelasi dalam bentuk asosiasi antara gastropoda dengan makroalga dengan menggunakan formula rank Spearman, kemudian membandingkannya di antara kedua lokasi studi. Kriteria pengambilan keputusan dan kriteria asosiasi dua variable berbeda mengacu pada Tabel 1.

Tabel 1. Kriteria pengambilan keputusan dan tingkat hubungan asosiasi berdasarkan nilai koefisien korelasi (Sudjana, 1996)

\begin{tabular}{cc}
\hline Rentang nilai & Kategori \\
\hline $0,00-0,20$ & hampir tidak ada asosiasi \\
$0,21-0,40$ & asosiasi rendah \\
$0,41-0,60$ & asosiasi sedang \\
$0,61-0,80$ & asosiasi tinggi \\
$0,81-1,00$ & asosiasi sempurna \\
\hline
\end{tabular}




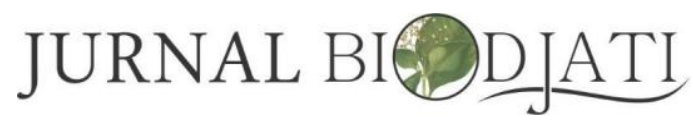

http://journal.uinsgd.ac.id/index.php/biodjati

\section{HASIL DAN PEMBAHASAN}

Hasil pengamatan menunjukkan total spesies makroalga yang ditemukan di wilayah Pantai Pasir Putih tercatat 12 spesies (Tabel 2), sementara di Pantai Batu Nunggul tercatat 11 spesies (Tabel 3). Persentase tutupan makroalga di Pantai Pasir Putih adalah 83\%, lebih kecil dibandingkan Pantai Batu Nunggul yang masih relatif lebih tinggi yaitu $98 \%$.

Tabel 2. Indeks ekologis komunitas makroalga di Pantai Pasir Putih

\begin{tabular}{clcc}
\hline No. & \multicolumn{1}{c}{ Spesies } & INP & \% Tutupan \\
\hline 1 & Acantophora spicifera (M. Vahl) Børgesen (1910) & 31,71 & 11,5 \\
2 & Borgesinia forbesii (Harvey) Feldmann (1938) & 5,38 & 1,5 \\
3 & Chaetomorpha crassa (C. Agardh) Kutzing (1845) & 4,78 & 1 \\
4 & Chaetomorpha antennina (Bory) Kützing (1847) & 9,60 & 5 \\
5 & Dictyosphaeria cavernosa (Forsskål) Børgesen 1932 & 15,62 & 10 \\
6 & Gracilaria coronopifolia J. Agardh (1852) & 4,78 & 1 \\
7 & Gracilaria salicornia (C. Agardh) E.Y. Dawson (1954) & 10,15 & 2,5 \\
8 & Halimeda opuntia (Linnaeus) J.V. Lamouroux (1816) & 5,38 & 1,5 \\
9 & Monostroma nitidum Wittrock (1866) & 11,36 & 3,5 \\
10 & Padina australis Hauck (1887) & 81,50 & 38 \\
11 & Turbinaria decurrens Bory (1828) & 5,98 & 2 \\
12 & Valoniopsis pachynema (G. Martens) Børgesen (1834) & 13,77 & 5,5 \\
\hline & Total & & 83 \\
\hline
\end{tabular}

Tabel 3. Indeks ekologis komunitas makroalga di Pantai Batu Nunggul

\begin{tabular}{clcc}
\hline No. & \multicolumn{1}{c}{ Spesies } & $\begin{array}{c}\text { INP } \\
(\%)\end{array}$ & $\begin{array}{c}\text { Tutupan } \\
(\%)\end{array}$ \\
\hline 1 & Acanthophora spicifera (M. Vahl) Børgesen (1910) & 20,43 & 5,5 \\
2 & Borgesinia forbesii (Harvey) Feldmann (1938) & 18,63 & 11 \\
3 & Chaetomorpha crassa (C. Agardh) Kützing (1845) & 4,72 & 1 \\
4 & Chaetomorpha antennina (Bory) Kützing (1847) & 13,53 & 6 \\
5 & Gracilaria coronopifolia J. Agardh (1852) & 92,01 & 57,5 \\
6 & Gracilaria eucheumatoides Harvey (1860) & 10,98 & 3,5 \\
7 & Gracilaria salicornia J. Agardh (1852) & 14,55 & 7 \\
8 & Halimeda macroloba Decaisne (1841) & 4,72 & 1 \\
9 & Halimeda opuntia (Linnaeus) J.V. Lamouroux (1816) & 9,96 & 2,5 \\
10 & Monostroma nitidum Wittrock (1866) & 4,72 & 1 \\
11 & Padina australis Hauck (1887) & 5,74 & 2 \\
\hline & Total & & 98 \\
\hline
\end{tabular}

Di Pantai Pasir Putih, seluas $48 \%$ dari area studi ditutup oleh spesies makroalga yang berasal dari divisi Phaeophyta. Di Pantai Batu Nunggul, $74 \%$ area studi didominasi oleh makroalga dari divisi Rhodophyta (Gambar 2).

Terdapat perbedaan spesies makroalga yang mendominasi di kedua stasiun pengamatan. Indeks Nilai Penting (INP) tertinggi dari makroalga di Pantai Pasir Putih adalah Padina australis, sedangkan di Pantai
Batu Nunggul adalah Gracilaria coronopifolia. Populasi makroalga di wilayah Pantai Pasir Putih didominasi oleh spesies Padina australis dengan presentase tutupan $38 \%$. Populasi makroalga di wilayah Pantai Batu Nunggul didominasi oleh spesies Gracilaria coronopifolia dengan presentase tutupan $57,5 \%$. Terdapat perbedaan luas tutupan total dari kedua stasiun pengamatan, yang menunjukkan bahwa Pantai Batu 


\section{Jurnal Biodjati, 2 (2) 2017

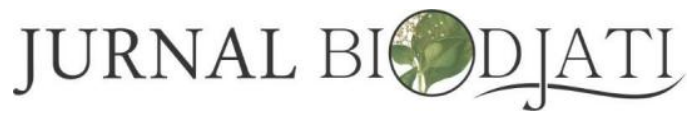

http://journal.uinsgd.ac.id/index.php/biodjati

Nunggul masih tertutup makroalga relatif lebih dari kedua lokasi studi, yaitu pasir dan baik dibandingkan Pasir Putih. Hal ini diduga karena adanya perbedaan karakteristik subtrat campuran pasir dengan karang masif.

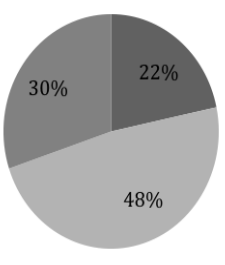

(A)

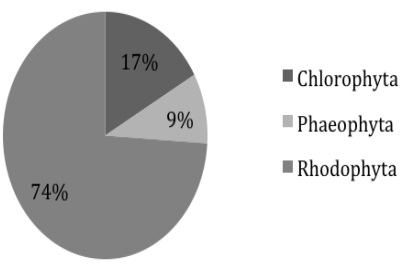

(B)

Gambar 2. Komposisi \% tutupan makroalga berdasarkan divisi di Pantai Pasir Putih (A) dan Pantai Batu Nunggul (B) di Pananjung Pangandaran

Dari pengamatan yang dilakukan, hasil menunjukkan total spesies gastropoda yang ditemukan di wilayah Pantai Pasir Putih tercatat sejumlah 7 spesies (Tabel 4), sementara di Pantai Batu Nunggul tercatat 8 spesies (Tabel 5). Indeks Nilai Penting (INP) tertinggi di Pantai Pasir Putih ditunjukkan oleh spesies Cypraea annulus yang juga memiliki kepadatan tertinggi. Spesies gastropoda di Pantai Batu Nunggul dengan INP dan nilai kepadatan tertinggi adalah Rhinoclavis sinensis.

Tabel 4. Spesies gastropoda di Pantai Pasir Putih Pananjung Pangandaran

\begin{tabular}{clcc}
\hline No. & \multicolumn{1}{c}{ Spesies } & $\begin{array}{c}\text { INP } \\
(\%)\end{array}$ & $\begin{array}{c}\text { Kepadatan } \\
\left(\mathrm{ind} / \mathrm{m}^{2}\right)\end{array}$ \\
\hline 1 & Astraea rhodoestoma Lamarck (1822) & 16,67 & 0,005 \\
2 & Cerithium articulatum A.Adams \& Reeve (1850) & 16,67 & 0,005 \\
3 & Cypraea annulus Linnaeus (1758) & 100,00 & 0,06 \\
4 & Engina alveolata Kiener (1836) & 16,67 & 0,005 \\
5 & Engina mendicaria Linnaeus (1758) & 16,67 & 0,005 \\
6 & Natica tigrina Röding (1798) & 16,67 & 0,005 \\
7 & Pyrene obtusa Sowerby (1832) & 16,67 & 0,005 \\
\hline
\end{tabular}

Tabel 5. Spesies gastropoda di Pantai Batu Nunggul Pananjung Pangandaran

\begin{tabular}{clcc}
\hline No. & Spesies & INP & Kepadatan \\
\hline 1 & Bursa elegans Sowerby (1841) & 11,56 & 0,005 \\
2 & Cerithium articulatum A.Adams \& Reeve (1850) & 36,02 & 0,03 \\
3 & Cypraea annulus Linnaeus (1758) & 29,57 & 0,02 \\
4 & Euplica scripta Lamarck (1822) & 11,56 & 0,005 \\
5 & Mitra pica Dillwyn (1817) & 11,56 & 0,005 \\
6 & Nassarius margaritifer Dunker (1847) & 14,78 & 0,01 \\
7 & Rhinoclavis sinensis Gmelin (1791) & 73,39 & 0,075 \\
8 & Quoyia decollata Quoy \& Gaimard (1833) & 11,56 & 0,005 \\
\hline
\end{tabular}

Berdasarkan hasil yang diperoleh, nilai indeks diversitas Shannon-Wiener dari gastropoda di kedua lokasi studi adalah 1,22 dan 1,52. Walaupun terdapat perbedaan, namun nilai keduanya termasuk pada rentang kriteria diversitas sedang (Krebs, 1985). 


\section{Jurnal Biodjati, 2 (2) 2017

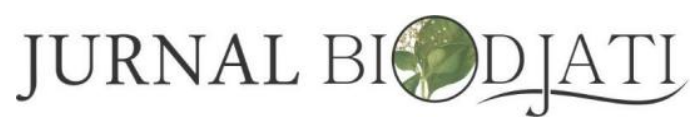

http://journal.uinsgd.ac.id/index.php/biodjati

Kepadatan Gastropoda dari kedua lokasi studi menunjukkan nilai yang sangat rendah, yang mengindikasikan degradasi populasi yang signifikan di kedua lokasi studi. Hal ini diperkirakan karena kedua lokasi studi tersebut mengalami frekuensi kunjungan wisata yang cukup tinggi, sehingga diduga aktivitas manusia tersebut mengganggu kehidupan gastropoda. Hal ini sejalan dengan penelitian Vinagre et al. (2016) yang menyatakan bahwa makroalga yang terpapar aktivitas antropogenik akan mengalami perbedaan struktur dan komposisi spesies dibandingkan dengan yang mengalami gangguan lebih kecil.

Adanya perbedaan nilai diversitas dan spesies Gastropoda yang ditemukan pada kedua lokasi studi diduga disebabkan perbedaan jenis substrat. Substrat pada Pantai Batu Nunggul adalah dominan pasir, sedangkan di Pantai Pasir Putih adalah campuran pasir dan karang. Tidak terdapat spesies gastropoda yang dominan di kedua stasiun pengamatan. Densitas keseluruhan gastrodpoda dari kedua stasiun pengamatan tidak menunjukkan nilai yang tinggi. Rendahnya nilai densitas gastropoda di kedua stasiun pengamatan diduga disebabkan oleh adanya paparan aktivitas antropogenik yang cukup intens, yaitu aktivitas pariwisata. Hasil yang diperoleh sejalan dengan penelitian yang menyatakan Gastropoda dan crustacea merupakan kelompok moluska yang rentan dan sensitif terhadap gangguan ataupun cekaman lingkungan (Terlizzi et al., 2005; dela-Ossa-Carretero et al., 2011), sehingga merupakan kelompok yang cepat turun densitasnya.

Kekayaan jumlah spesies makroalga dan gastropoda di Pantai Batu Nunggul masih lebih baik dibandingkan dengan Pantai Pasir Putih (Tabel 6). Nilai Indeks Diversitas Shannon-Wiener di kedua stasiun pengamatan tidak menunjukkan perbedaan karena keduanya tidak masuk pada kriteria baik. Dari nilai Indeks dominansi Simpson terlihat bahwa ada dominansi pada komunitas gastropoda di kedua stasiun pengamatan, sedangkan pada komunitas makroalga tidak terjadi dominansi.

Tabel 6. Indeks ekologis komunitas makroalga dan gastropoda di Pantai Pasir Putih dan Pantai Batu Nunggul Pananjung Pangandaran

\begin{tabular}{|c|c|c|c|c|c|}
\hline \multirow{2}{*}{ Indeks } & \multirow{2}{*}{ Standar nilai } & \multicolumn{2}{|c|}{ Pantai Pasir Putih } & \multicolumn{2}{|c|}{ Pantai Batu Nunggul } \\
\hline & & Makroalga & Gastropoda & Makroalga & Gastropoda \\
\hline Kekayaan Spesies $^{1)}$ & $4=$ baik $^{1)}$ & 0,93 & 0,78 & 1,64 & 1,43 \\
\hline $\begin{array}{l}\text { Diversitas Shannon- } \\
\text { Wiener }\left(\mathrm{H}^{\prime}\right)^{2)}\end{array}$ & $>3=$ baik $^{2)}$ & 1,49 & 1,22 & 1,39 & 1,52 \\
\hline Dominansi Simpson $(\lambda)^{3)}$ & $0=$ tidak ada dominansi ${ }^{3)}$ & 0,26 & 0,46 & 0,36 & 0,55 \\
\hline
\end{tabular}

I) Jorgensen et al., (2005); ${ }^{2)}$ Shannon-Wiener (1949); ${ }^{3)}$ Odum (1993)

Berdasarkan hasil yang diperoleh, nilai koefisien korelasi yang menunjukkan terdapat korelasi dengan tingkat asosiasi yang berbeda antara makroalga dengan gastropoda di kedua lokasi studi (Tabel 7).

Tabel 7. Nilai asosiasi antara makroalga dengan gastropoda di Pantai Pasir Putih dan Pantai Batu Nunggul, Pananjung Pangandaran

\begin{tabular}{ccc}
\hline Nilai & Pantai Pasir Putih & Pantai Batu Nunggul \\
\hline Koefisien korelasi & 0,235 & 0,468 \\
Kriteria* & Asosiasi rendah & Asosiasi sedang \\
\hline
\end{tabular}




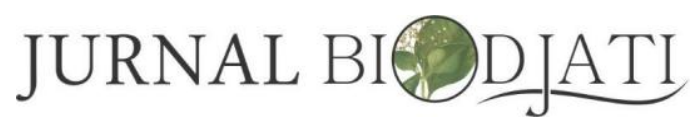

http://journal.uinsgd.ac.id/index.php/biodjati

Interaksi yang terjadi antara makroalga dan hewan gastropoda dalam bentuk asosiasi di kedua lokasi studi berlangsung positif, walaupun keeratan asosiasinya masuk dalam kategori rendah dan sedang. Dalam hal ini berarti kedua populasi akan hadir secara bersamaan dalam habitat yang sama, namun tidak terdapat pengaruh yang besar antara tutupan makroalga terhadap kepadatan jenis gastropoda. Interaksi yang terjadi adalah bentuk asosiasi yang menunjukkan kedua belah pihak mengalami keuntungan, tetapi tidak terjadi faktor ketergantungan. Gastropoda memanfaatkan makroalga sebagai salah satu sumber makanannya serta sebagai salah satu alternatif tempat berlindung. Selain memanfaatkan makroalga sebagai tempat berlindung, Gastropoda juga dapat berlindung di sela-sela karang masif yang kadang membentuk tide pools, sehingga tidak tergantung sepenuhnya pada makroalga. Hal ini yang mungkin dapat menjelaskan asosiasi pada pantai Pasir Putih. Hal ini sedikit berbeda pada Pantai Batu Nunggul, karena subtratnya didominasi pasir, maka makroalga menjadi tempat berlindung yang signifikan dari gastropoda, sehingga nilai asosiasinya lebih besar dibandingkan dengan Pasir Putih.

Sementara itu, keberadaan Gastropoda memiliki peran bagi makroalga, terutama dalam siklus nutrien. Secara tidak langsung, keberadaan gastropoda yang mengeluarkan feses dan mempercepat proses degradasi fisik materi organik menghasilkan mineral-mineral yang dibutuhkan dalam fotosintesis dan berperan dalam perkembangbiakannya dengan membantu penyebaran spora makroalga (Leitte \& Turra, 2003). Hal ini sejalan dengan Hayes (2007) yang menyatakan bahwa di daerah pasang surut distribusi makroalga berkaitan erat dengan keberadaan gastropoda.

Perbedaan kategori asosiasi di kedua lokasi penelitian dipengaruhi oleh berbagai faktor, seperti faktor substrat dan aktivitas manusia. Intensitas aktivitas manusia juga diduga memengaruhi tingkat asosiasi yang terjadi ketika kedua lokasi studi merupakan wilayah aktif ekowisata sehingga banyak wisatawan yang melakukan aktivitas di pesisir pantai dan mengganggu keseimbangan ekosistem, termasuk terhadap dua populasi tersebut. Diharapkan studi ini dapat memberikan masukan bagi arah pengelolaan Pananjung Pangandaran yang lebih baik.

\section{DAFTAR PUSTAKA}

BKSDA Taman Wisata dan Cagar Alam Pangandaran. (2016). Profil Resor Konservasi Wilayah XX Pangandaran.

Brower, J. E., Zar, J. \& Ende, C. N. V. (1998). Fields and Laboratory Method for General Ecology. WCB McGraw-Hills, Boston.

de-la-Ossa-Carretero, J. A., Del-Pilar-Ruso, Y., Gimenes-Casalduero, F., SanchezLizaso. \& Dauvin, J. -C. (2011). Sensitivity of Amphipods to Sewage Pollution. Estuarine, Coastal and Shelf Science. xxx: 1-10.

English, S., Wikkinson,C. \& Backer, V. (1994). Survey Manual for Tropical Marine Resources. 2nd Edition. Australian Institute of Marine Science, Townsville.

Gomez, E.D. \& Yap, H. T. (1988). Monitoring Reef Condition. In Kenchington R. A. \& Hudson, B.E.T. (eds). Coral Reef Management Hand Book. UNESCO. Regional Office for Science and Technology for Southeast Asia. Jakarta.

Guidone M.,C., Thomber, C. \& Field, E. (2010). Snail Grazing Facilitates Growth of a Bloom-Forming Alga. Marine Ecology Progress Series. 420 (2): 83-89.

Hayes, C. (2007). Vertical Distribution of Algal Species in Rock Pools in South- 


\section{JURNAL BIODJATI}

http://journal.uinsgd.ac.id/index.php/biodjati

Eastern Australia. Cross Sections 3: 33-

49.

Jorgensen S, E., Costanza, R. \& Xu, F. -L. (2005). Handbook of Ecological Indicators for Assesement of Ecosystem Health. CRC Press, Florida.

Krebs, C. J. (1985). Ecology: The Experimental Analysis of Distribution and Abundance. Harper and Row, New York.

Leitte, F. P. P. \& Turra, A. (2003). Temporal Variation in Sargassum Biomass, Hypnea epiphytism and Associated Fauna. Brazilian Arch Biol and Technol. 46 (4): 665-671.

Odum, E. P. (1993). Dasar-dasar Ekologi. Edisi Ketiga. Alih Bahasa T. Samingan. Gadjah Mada University Press. Yogyakarta. Hal. 5-10.

Shannon, C. E, \& Weaver, W. (1949). The Mathematical Theory of Communication. University of Illinois Press, Illinois.

Terlizzi, A., Scuderi, D., Fraschetti, S. \& Anderson, M. J. (2005). Quantifying effects of pollution on biodiversity: a case study of highly diverse molluscan assemblages in the Mediterranea. Marine Biology. 148: 293-305.

Vinagre, P. A., Pais-Costa, A. J., Gaspar, R., Borja, A., Carios, J. C. \& Neto, J. M. (2016). Response of Macroalgae and Macroinvertebrates To Anthropogenic Gradient Disturbance in Rocky Shore. Ecological Indicators. 61 (850-864).

Yulianda, F. (2013). Zonation and Density of Intertidal Communities at Coastal Area of Batu Hijau, Sumbawa. Jurnal Ilmu dan Teknologi Kelautan Tropis. 5(2): 409-416. 